\title{
Blood levels of the omega-3 fatty acid docosahexaenoic acid are associated with gait and lower limb power in older females
}

\author{
S. C. Dyall ${ }^{1}$, A. Carlisle ${ }^{1}$, E. L. Gibson ${ }^{2}$ and S. Strike ${ }^{1}$ \\ ${ }^{1}$ Department of Life Sciences, University of Roehampton, London SW15 4JD UK and ${ }^{2}$ Department of Psychology, \\ University of Roehampton, London SW15 4JD UK
}

Walking performance is a key determinant of frailty in older adults ${ }^{(1)}$ and reduced muscle strength in walking is associated with poor motor performance, postural instability and a risk of falling amongst older adults and may dissuade individuals from activity participation. Vertical Jump Height (VJH) analysis is a useful movement model and has been studied extensively in relation to muscle power and strength. Omega-3 fatty acid supplementation improves walking speed in older females ${ }^{(2)}$, and may represent a potential intervention for the prevention and treatment of sarcopenia ${ }^{(3)}$. The present study analysed the relationship between blood levels of the omega-3 fatty acid, docosahexaenoic acid (DHA) and gait, functional strength and lower limb power in older females.

A Vicon 9 motion capture camera system synchronised with Kistler force plates was used to analyse the relationship between self-selected habitual (normal) and fast walking and VJH and blood levels of DHA in 28 postmenopausal women (mean age 67 years, S.D. 6 years). Liner regression models were performed for the movement outcome variables, with whole-blood DHA content ( $\%$ total fatty acids) the predictor variable. Other factors included in the models were age, Body Mass Index (BMI), self-reported physical activity (PASE) $)^{(4)}$ and grip strength.

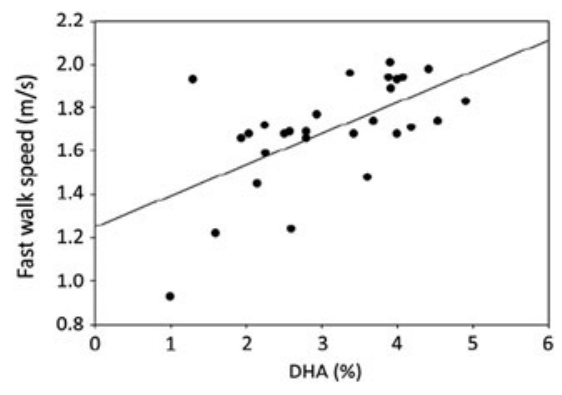

Fig. 1 Fast walk

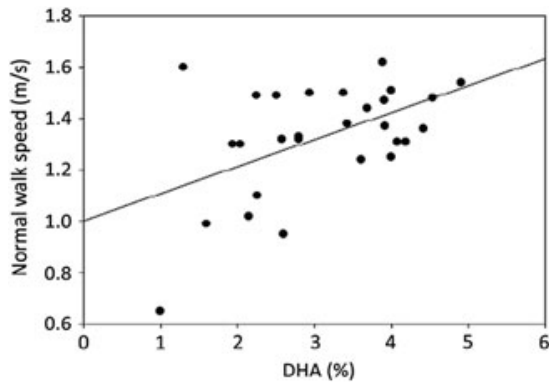

Fig. 2 Normal walk

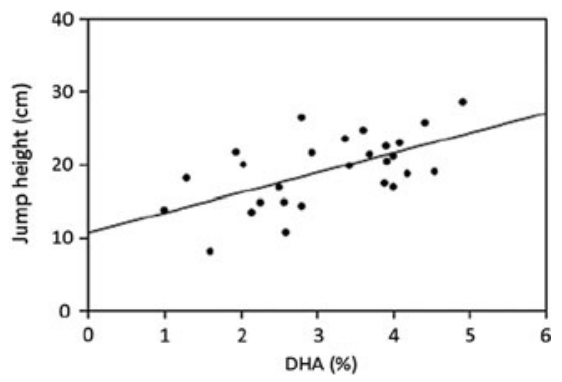

Fig. 3 VJH

With normal walking there were no significant effects for BMI, age or grip strength and these were progressively removed from the model based on the largest $\mathrm{P}$ values and the analysis repeated. DHA (Fig. 1) (coefficient $0 \cdot 10,[95 \% \mathrm{CI} 0 \cdot 41,0 \cdot 16], \mathrm{P}=0 \cdot 002$ ) and PASE $(0.003,[0.00,0.00], \mathrm{P}=0.001)$ remained significant, with the model explaining $51 \%$ of the variance. Similarly for fast walking the only significant effects were also with DHA $(0 \cdot 14,[0 \cdot 07,0 \cdot 21], \mathrm{P}<0.001)$ (Fig. 2) and PASE (0.002, [0.00, 00], P<0.05), explaining $46 \%$ of the variance. With $\mathrm{VJH}$ the effects of age, DHA (Fig. 3) and BMI remained significant after adjustments $(-0 \cdot 32,[-0.54,0 \cdot 10], \mathrm{P}=0 \cdot 07),(1.92,[0 \cdot 72,3 \cdot 13], \mathrm{P}=0.003)$ and $(-0 \cdot 76,[-1 \cdot 16,-0 \cdot 37], \mathrm{P}=0 \cdot 001)$, respectively, explaining $69 \%$ of the variance.

These results show that with both self-selected habitual and fast walking speeds higher circulating DHA along with physical activity levels are important contributory factors. Higher circulating DHA is also associated with high power, high velocity movements, assessed using VJH, though here, the high demand movement was also related to age and BMI. Interestingly, grip strength was not a factor for any movement, suggesting that hand grip strength is not related to whole-body functional movement strength and power.

This work was supported by Efamol Ltd/Wassen Intl Ltd.

1. Rothman MD, Leo-Summers L, Gill TM. (2008). J Am Geriatr Soc. 56, 2211-116.

2. Hutchins-Wiese HL, Kleppinger A, Annis K, et al. (2013). J Nutr Health Aging. 17, 76-80.

3. Smith GI, Atherton P, Reeds DN, et al. (2011). Am J Clin Nutr. 93, 402-12.

4. Washburn RA, Smith KW, Jette AM, et al. (1993). J Clin Epidemiol. 46, 153-62. 